\title{
ANTIGUIDADE TARDIA: IMAGEM E DOCUMENTO
}

\author{
Cláudio Umpierre Carlan ${ }^{1}$
}

\section{Resumo:}

O artigo começa com uma descrição da iconografia como documento histórico. A imagem na Antiguidade tinha uma função específica: apresentar a um determinado grupo social, maioria analfabeto, algo que representasse a orla do poder. Ela não apenas legitimava um imperador ou rei, funcionava como uma espécie de propaganda política.

\section{Palavras-Chaves}

Moeda; poder; Roma; iconografia;

1 Professor Doutor. Universidade Federal de Alfenas - Alfenas, MG, Brasil. e-mail: claudiocarlan@yahoo.com.br 


\begin{abstract}
The article begins with a description of the iconography as document history. The image in Antiquity had a specific function: to present a particular social group, mostly illiterate, something that represented the edge of power. She not only legitimized an emperor or king, was a kind of propaganda.
\end{abstract}

\title{
Keywords
}

Money; power; Rome; iconography. 


\section{Introdução}

A imagem na Antiguidade tinha uma função específica: apresentar a um determinado grupo social, algo que representasse a orla do poder. Ela não apenas legitimava um imperador ou rei, funcionava como uma espécie de propaganda política.

A moeda tem sido estudada pelos historiadores sob o prisma de mercadoria, objeto de troca. Procurou-se ligá-la com a história social, ou seja, com os reflexos que a mutação monetária produzia na sociedade, nível de salários, custo de vida e os consequentes comportamentos coletivos perante estes. $\mathrm{O}$ estudioso da moeda se tem preocupado mais com o corpo econômico e social que ela servia do que com o metal que a produzia e a informava. Estruturalmente, este ultrapassava os limites geográficos do poder que a emitia e definia ideologicamente não só um povo, mas também a civilização a que este pertencia.

O homem contemporâneo dificilmente pode ligar a moeda a um meio de comunicação entre povos distantes. Ao possuidor de uma determinada espécie monetária estranha, esta falava-lhe pelo metal nobre ou não em que era cunhada, pelo tipo e pela legenda. O primeiro informava-lhe a riqueza de um reino e os outros dois elementos diziam-lhe algo sobre a arte, ou seja, o maior ou menor aperfeiçoamento técnico usado no fabrico do numerário circulante, sobre o poder emissor e, sobretudo, sobre a ideologia políticoreligiosa que lhe dava o corpo. È dentro deste último aspecto que pretendemos explorar a fonte numismática.

\section{A Numismática" como fonte: lendo a "moeda."}

A numismática ligou-se tradicionalmente ao estudo da História, sobretudo a História Política, ajudando a estabelecer a cronologia de reinados e a datar fatos importantes da política; à Economia, informando sobre o valor das moedas dentro dos diferentes sistemas monetários; à Arqueologia, contribuindo para auxiliar a datação de estratos e

2 Todos as fontes numismáticas aqui analisadas, pertencem ao acervo do Museu Histórico Nacional, com sede no Rio de Janeiro. O museu possui a maior coleção de moedas da América Latina. 
sítios arqueológicos; e à História da Arte, permitindo, através de seus tipos, uma análise da evolução dos estilos e o reconhecimento de obras desaparecidas ou conhecidas somente por meio de textos literários (Vieira: 1995, 94) 3 .

Nesse sentido, a numismática não está restrita aos museus, apesar de durante décadas estar "presa" a catálogos e acervos guardados a sete chaves. Ela parte de um interesse mais amplo, colaborando com diversas disciplinas, auxiliando nas mais variadas pesquisas, tanto arqueológicas quanto relacionadas com a Antiguidade Clássica ou demais períodos históricos. Trata-se de um veículo propagandístico, com mensagens, arte, religião (magias e superstições), ideologia e política.

A utilização das moedas como fonte não é novidade. Não pretendemos aqui explorar todos aqueles que trilharam esse caminho, mas citaremos alguns autores que trabalharam com tal documentação. Quanto a nós, analisaremos a propaganda política representada pela iconografia, através de uma análise simples de conteúdo, tratando de identificar as conotações tanto históricas quanto estéticas.

Com identificação prévia da documentação disponível e na catalogação, estabelecemos um corpus documental. Para isso, seguimos a categorização conhecida como "esquema de Lasswell", pioneiro, desde 1927, das análises de conteúdo aplicadas à política e à propaganda. Relacionamos o corpus com: a natureza do emissor; a quem se destina tais representações; e o seu significado.

\section{Primeira etapa da análise de conteúdo: análise prévia da documentação disponível e estabelecimento de um corpus documental ao qual será aplicado aquele método ${ }^{4}$.}

Mesmo já tendo decidido - função de características que percebe na documentação disponível pertinente às hipóteses que formulou e de que pretende obter a comparação (ou a refutação) - aplicar alguma modalidade de análise de conteúdo, a posição do historiador diante de suas fontes é, quanto a isso, imprecisa e intuitiva de início. Ele sabe em que direção e partindo de quais perguntas se vai orientar, mas ainda ignora em que consistirá o suporte de sua análise de conteúdo - pelo menos, não o sabe necessariamente, a não ser que esteja mais ou menos repetindo, para outro caso e outro corpus, algum tipo de aplicação já bem conhecido e testado alhures.

\footnotetext{
${ }^{3}$ Rejane Maria Lobo Vieira foi durante muitos anos encarregada da Seção de Numismática. Realizou um trabalho pioneiro sobre as moedas de D. Fernando de Portugal, último governante da Dinastia de Borgonha.

${ }^{4}$ Notas das aulas do Professor Ciro Flamarion Cardoso.
} 
Certos critérios devem ser satisfeitos para que a análise de conteúdo possa ser aplicada com sucesso. Será preciso renunciar a certas fontes: as que não formarem uma série completa para os fins da aplicação; e/ou apresentarem uma natureza pouco adequada ao método; e/ou não forem homogêneas. Com efeito, a escolha de um corpus documental ao qual aplicar alguma forma de análise de conteúdo passa por estes três critérios principais: 1) o corpus em questão deve ser completo no sentido exigido pela natureza do tema e das hipóteses; 2) deve ser uma documentação que, em seus conteúdos e em suas dimensões, justifique ser pertinente o uso da análise de conteúdo; 3) deve ser homogênea segundo princípios que se definam. Nesta fase pré-analítica, é frequente que o pesquisador hesita entre diversos conjuntos documentais, faça tentativas parciais de aplicação do método para avaliar os resultados assim obtidos e, em função destes, os que se conseguiriam com uma aplicação detalhada ou total.

Ao cabo desta primeira etapa, o pesquisador disporá então de um corpus documental constituído de um só documento ou, o que é mais provável, de vários: mas, no segundo caso, é preciso poder justificar o fato de considerá-los como uma espécie de

supertexto suficientemente homogêneo constituído por textos individuais. Em certos casos, é possível e necessário distinguir entre o corpus total e o corpus pertinente: isto é, entre a documentação que integra o corpus em questão vista em sua totalidade, por um lado, e, por outro, o recorte parcial dela ao qual, devido aos contornos da pesquisa (delimitação do tema, objetivos, hipóteses), for de fato útil aplicar a análise de conteúdo.

\section{Segunda etapa da análise de conteúdo: a categorização.}

Antes de passar a esta etapa, é preciso aplicar ao corpus escolhido a operação conhecida como "esquema de Lasswell”, conforme já explicamos na página anterior.

Existe, na análise de conteúdo de qualquer tipo, um postulado (ou hipótese teórica de base) nem sempre explicitado pelos pesquisadores: a afirmação de que haja, nos textos interrogados mediante este método, algum significado não imediatamente dado, evidente ou visível e que só a análise revelará. Outrossim, é preciso preocupar-se com a necessidade de não desnaturar, não falsificar os conteúdos contidos nos textos ao aplicar-lhes o método de análise. Em suma, há de início duas exigências: de originalidade de saber tratar os textos de um modo que responda a perguntas ou problemas não formulados antes em relação a eles; e de fidelidade aos conteúdos efetivamente presentes no corpus.

A operação central é, nesta etapa, o estabelecimento de uma grade ou rede de categorias. A partir de uma leitura prévia do corpus completo, com atenção voltada constantemente para o que for útil à pesquisa (delimitação do objeto, objetivos, problema formulado, hipóteses), registram-se os elementos pertinentes observáveis nele, distinguindo-os em temas ou categorias temáticas que possam, eventualmente, 
ser computados e, sobretudo, que permitam comparações significativas entre os diferentes textos integrantes do corpus (ou, se tratar de um só documento de ampla extensão, entre diferentes partes desse documento). Na verdade, uma análise de conteúdo valerá aquilo que valerem as categorias segundo as quais for realizada quanto ao que tragam efetivamente à pesquisa em curso, bem como no tocante ao grau de fidelidade que observem diante dos conteúdos documentais.

Uma boa categorização tem como condição prévia sine qua non uma compreensão adequada dos conteúdos semânticos dos textos do corpus; e tal compreensão só ocorrerá se o pesquisador possuir familiaridade e informações suficientes acerca da época em estudo e de seu universo mental. A formação que representa, por exemplo, a análise de conteúdo é uma segunda leitura fundamentada em outra: uma primeira leitura ou decodificação, ou mais simples e mais básica, que depende de conhecer-se a língua e a cultura da época em que se geraram os textos. Sem esta primeira leitura feita adequadamente, as categorias escolhidas dificilmente serão pertinentes e profícuas. Tais categorias são conceitos de nível superior (secundários, "supraordenados"), enquanto os conceitos obtidos na primeira leitura ou decodificação são de nível primário: os primeiros dependem necessariamente destes, embora possam reuni-los em esquemas mais amplos.

As categorias temáticas selecionadas para a análise, estabelecidas pelo pesquisador no final de um processo às vezes longo de ensaio e erro, correções e renúncias, devem responder a quatro critérios principais: pertinência, exaustividade, exclusividade e objetividade.

A pertinência é dada pela medida em que as categorias escolhidas tiverem a capacidade de refletir escrupulosamente os conteúdos do corpus e, ao mesmo tempo, de expressar a problemática do processo de pesquisa em função do qual se aplique a análise de conteúdo.

A exaustividade das categorias se dá quando, no seu conjunto, permitam interrogar a totalidade do corpus (ou parte do mesmo pertinente à pesquisa). Em certos casos, não se consegue uma exaustividade completa, restando algumas categorias para acomodar porções "inclassificáveis" do mencionado corpus: mas estas devem ser residuais, ter dimensões reduzidas no relativo à parte do corpus que nelas entrem.

A exclusividade significa que elementos idênticos de conteúdo não devem aparecer em mais de uma categoria: a relação categoria/conteúdo deve ser discreta ou excludente. De novo: se não for possível uma exclusividade total, para que o trabalho funcione adequadamente é preciso pelo menos chegar perto dela.

A objetividade é somente tendencial, mesmo porque diferentes pesquisadores podem chegar a diferentes categorias em relação a um mesmo corpus, cada um deles 
defendendo as suas como sendo mais fiéis aos conteúdos efetivos do mesmo. Pelo menos, seria preciso que um leitor informado, mesmo que preferisse uma grade de categorias diferente no todo ou em parte da que elaborou o pesquisador, aceitasse que o analista registrou adequadamente cada unidade de conteúdo nas categorias que formulou. Espera-se, naturalmente, que o autor estabeleça e defenda sua objetividade mediante um espírito crítico sempre ativo manifestado diante de seu próprio trabalho, pela clareza com que exponha o encaminhamento e a justificativa das categorias que estabeleceu. Em especial, cabe ao pesquisador precisar alguns indicadores que informem ao leitor as razões de suas escolhas em matéria de categorização. Segundo Berelson, "as hipóteses devem exprimir o problema o mais adequadamente que for possível; as categorias devem fazer o mesmo em relação às hipóteses; e os indicadores, em relação às categorias (Berelson: 1952, 78) "

\section{Terceira etapa da análise do conteúdo: codificação e cômputo das unidades.}

Para possibilitar a aplicação das categorias ao corpus, é preciso delimitar as unidades que determinarão os recortes a fazer no mesmo. Em geral se distinguem as unidades de registro de contexto.

Unidade de registro é o segmento de conteúdo que o pesquisador decidiu tomar como menor unidade de sua grade de leitura e análise: uma palavra, um grupo de palavras, um parágrafo, um semema, etc. Sua dimensão pode, pois, variar segundo os critérios de recorte que houveram sido introduzidos na dependência da natureza e dos objetivos da análise de conteúdo.

Unidade de Contexto é a unidade imediatamente superior em suas dimensões à unidade de registro. Sua finalidade é permitir optar por uma determinada categoria onde classificar uma dada unidade de registro, em caso de dúvida.

\section{Quarta etapa da análise de conteúdo: a interpretação dos resultados.}

Nesta etapa é que ficarão patentes - se for o caso - a fecundidade das escolhas de método operadas e a pertinência das hipóteses de trabalho. "Interpretação", no sentido do termo que aqui interessa, é uma leitura nova (original) e objetiva do corpus, apoiada nas etapas Segunda e terceira acima e, também, nos conhecimentos do pesquisador acerca do período estudado, do tema tratado, do contexto em que se insere, etc. segundo Lasswell, teríamos aqui outra pergunta a propor: com que resultados os textos foram formulados e circulam? (Lasswell: 1965, 95). No entanto, nem sempre é esta a intenção: pode-se tentar, simplesmente, "ler" determinada ideologia, representação, imaginário no corpus, mesmo ao se tratar, eventualmente, de documentos que não tiveram importante circulação para, deste modo, vir a entender melhor algum tema. 
Interpretar é inferir: uma operação lógica por meio da qual, de uma ou mais proposições - no caos presente, os dados estabelecidos ao terminar o processo da análise de conteúdo aplica ao corpus - se retira uma ou mais consequências que resultem necessariamente daquelas proposições. Trata-se aqui, de voltar às hipóteses para, por meio dessa inferência, avaliar até que ponto forma comprovadas. Caso uma ou mais hipóteses hajam sido, pelo contrário, refutadas pelos resultados da análise de conteúdo, será preciso verificar a razão de tal coisa ter acontecido e, conforme as circunstância, completar, modificar parcialmente ou substituir as hipóteses em questão; e, a seguir, recomeçar a análise ou pelo menos, introduzir nela as consequências de tais operações.

Realizamos uma comparação significativa entre as diferentes imagens contidas no reverso de cada moeda, fazendo uma primeira leitura ou decodificação dos símbolos existentes. Assim, foi possível encontrar e identificar determinados elementos que representavam a ideologia política, militar ou religiosa da época.

Em tais representações, política e estética estavam intimamente ligadas em Roma. As moedas associavam-se tanto à propaganda ideológica quanto à política. As peças não apenas são instrumentos importantes para estabelecer a datação de documentos que chegaram até nós sem seu contexto original, como têm grande valia, em si mesmas, por meio de nossa compreensão desses "retratos" de uma realidade antiga. Com frequência, o tipo monetário de reverso mostra determinada reprodução artística. Ainda que o seu significado, em alguns casos indicado pela legenda que a acompanha, ou pelo tipo do anverso, possa aparecer com uma interpretação original em relação ao modelo, muitas vezes tipos monetários e modelo têm o mesmo sentido.

Estas práticas do poder- e seus simbolismos- atuam, de uma maneira direta ou não, através de questões ideológicas. E, em toda uma sociedade, através das ideias da classe dominante, predominam, oralmente ou escrita. Cardoso diz que "...é de especial interesse e bem esclarecedor o estudo dos mecanismos que asseguram e reproduzem a hegemonia ideológica..." (Cardoso: 1979, 397).

Podemos verificar uma resistência tenaz das antigas formas de administração e de comunicação. Na própria Inglaterra do século XII, apesar dos progressos quanto ao domínio da leitura e da escrita, a palavra ouvida e o gesto visto permanecem a expressão essencial do poder de comando e justiça. (Chartier: 1990, 218).

Não podemos esquecer que a história deve sempre procurar explorar o seu objeto a partir da análise dos diferentes elementos nela intervenientes, aberta a uma nova linguagem, às novas interrogações que cada época faz ao passado:

Engajar-se no presente, dar ouvidos a todos os seus rumores - numa palavra, viver - exige que o historiador se mantenha informado sobre o que descobre $e$ 
se transforma no campo das ciências vizinhas. A história se enfraqueceria isolando-se. (Duby: 1986, 190)

Umberto Eco, em sua obra Tratado Geral de Semiótica, explica que é na própria estrutura do código, onde a semiótica propõe o problema do estudo da configuração sintática do código como nascente de uma informação sígnica (Eco: 1980, 194). Estes conjuntos de objetos, no caso as moedas e seus símbolos, produzidos pela ação do homem e mediante ordem de alguém, o emissor, devem ser entendidos pelo destinatário, o receptor, como uma expressão de um dado conteúdo. Podendo ser por uma correlação anteriormente codificada, em outras peças chamadas de variantes, ou por causa de uma possível correlação diretamente por parte deste receptor.

Tal relação emissor/receptor é nitidamente identificada nas cunhagens realizadas durante o início do século IV. Diocleciano, Galério, Constâncio Cloro, Maximiano, Severo Augusto e Maximino Daia cunharam moedas com tipos semelhantes: GENIO AVGVSTI, GENIO POPVLI ROMANI, VIRTVTI EXERCITVS, CONCORDIA MILITVM, SAC MON VRB AVGG ET CAESS NN, VOT XX E; entre outras. Defendiam a salvação do império num retorno ao passado e as suas divindades, impondo tal ideologia através de um veículo propagandístico com o qual toda a população teria contato: a própria moeda. Esses signos externos correspondentes a tais hierarquias eram utilizados para diferenciar um governante de outro. Recordemos que uma simples faixa de tecido ao redor da cabeça era o emblema que distinguia os generais de Alexandre, que repartiram seus domínios e governaram como verdadeiros monarcas.

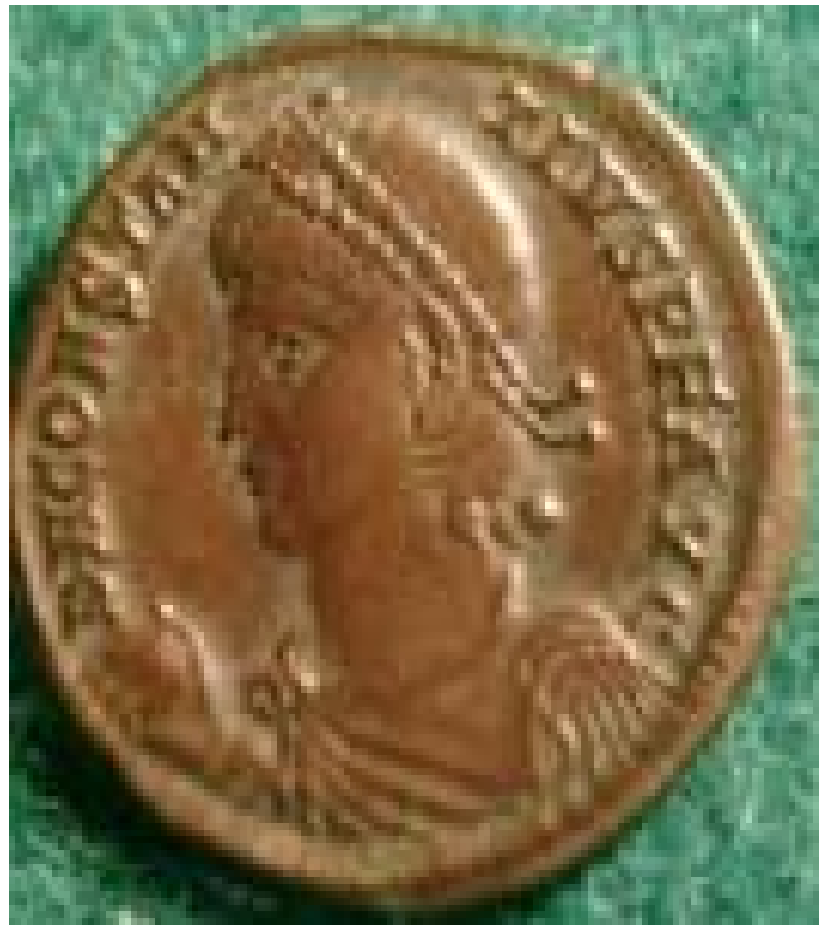




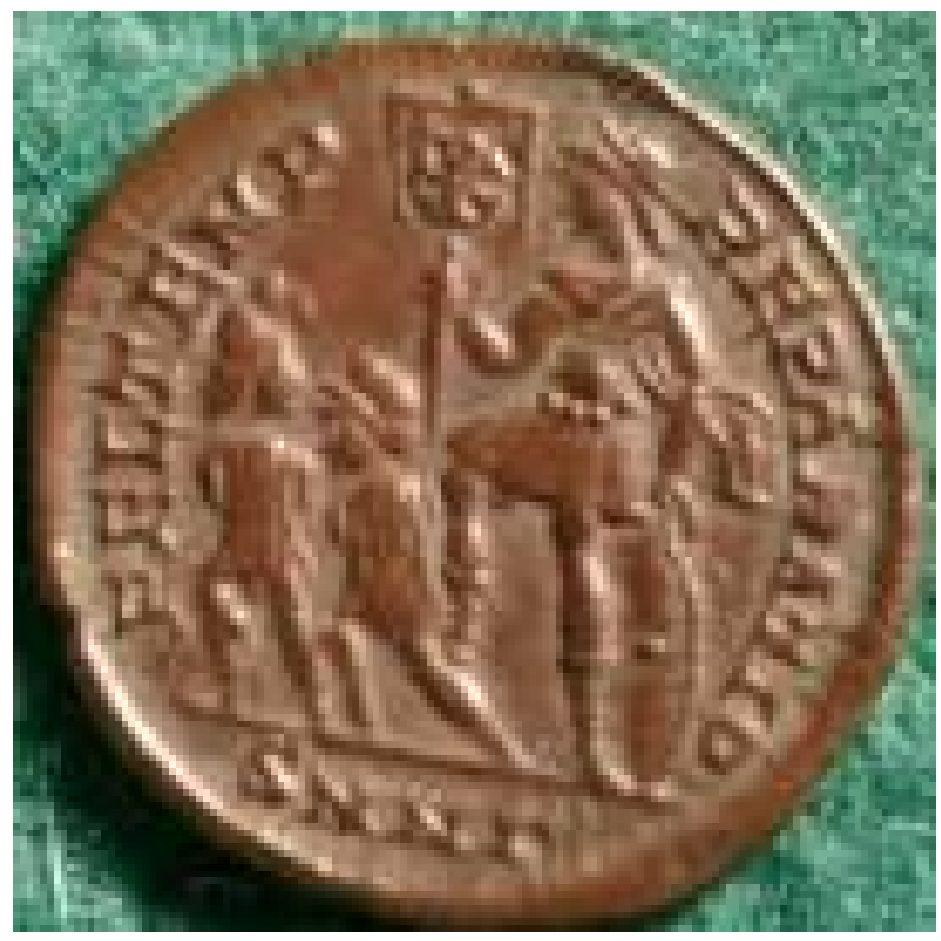

FOTO CLÁUDIO UMPIERRE CARLAN. ACERVO NUMISMÁTICO DO MUSEU HISTÓRICO NACIONAL, RIO DE JANEIRO, JUNHO DE 2000.

\section{Descrição da Moeda}

ANVERSO: DN CONSTAN-TIVS PF AVG - busto de Constâncio II, diademado à direita. Nessas cunhagens, centenional, o imperador é representado com manto, globo na mão direita. Globo, símbolo da perfeição e do poder imperial, levado em uma das mãos, representa domínio ou o território sobre o qual se estende a autoridade do soberano (Chevalier; Gheernrant; 1997, 472). Centenionalis eram moedas de bronze cunhadas por Constantino I, o grande, pai de Constâncio II, a partir do ano de 330, pesando aproximadamente 4 gramas. Essa denominação foi dada no século XIX. Nome original dessa cunhagem ainda é desconhecida.

REVERSO: FEL TEMP REPARATIO - Imperador, com armadura de combate, dominando dois prisioneiros germânicos. Na mão direita, lábaro com sinal de Constantino, X (chi) e P (rho), presente em outras cunhagens do período. Constâncio, em tamanho maior que os dois prisioneiros, por ser centro do poder real, pisa no joelho de um dos cativos. Outro, olha o estandarte em sinal de submissão, tanto a Roma, quanto ao Cristianismo. Símbolos cristãos tornaram-se comuns nas cunhagens do 
século IV a partir do ano de 317. No exergo ou linha de terra, $\mathrm{SNN} \Gamma$ referente à casa monetária de Nicomédia. Peso: 3,78 g; diâmetro 2,02 mm; alto reverso ou linha de terra 6 horas.

Para Pastoureau, a "escrita circular" é pouco estudada. As legendas monetárias foram vistas e manuseadas por indivíduos das mais variadas condições sociais (Pastoureau: 1988, 125). Mas o texto tocado pelas pessoas, não significa que foi lido. O autor pretende dar uma maior importância às inscrições do que o tipo da moeda, representado no reverso, onde estaria localizado o maior número de informações em um pequeno espaço.

Essas legendas eram abreviaturas em latim, relacionadas com as imagens de anverso e reverso, ocorrendo assim a união escrita/imagem. O receptor daquela peça saberia identificar o seu governante, suas mensagens simbólicas. Existiam todas as espécies de signos, figuras geométricas, signo de pontuação, astros, animais, vegetais, brasões, que levavam uma mensagem governante/governado ao vasto mundo romano.

Nas representações políticas, a riqueza iconográfica está mais destacada no período da tetrarquia, mas não negligenciaremos os outros períodos da História Romana. Como exemplo, PROVIDENTIA DEORVM, IOVI / HERCVLES (Diocleciano e Maximiano juntos), VIRTVTI AVGG, PAX (figura feminina), PRINCI A INVENTVTIS, BEATA (Altar com os votos nas amoedações de Crispus), PROVIDENTIA CAESS (campo militar ou fortaleza, Constantino I e II, Constâncio II, Galo, Constante, Valentiniano I), a loba amamentando Rômulo e Remo (sem legenda, Constantino), PROVIDENTIA AVGG (campo militar, Licínio), IOVI / CAESAR, VIRTVS (Licínio filho), CASTOR / POLVX (Maxêncio); templo com a cúpula redonda, sem legenda, cunhado após à morte do filho de Maxêncio, Rômulo, ainda criança (alusão a nomeação de César no anverso).

A moeda mostra-se uma excelente fonte, pois, a partir de sua análise encontramos diversos aspectos que abrangem a série na sua totalidade. Ou seja, aspectos políticos, estatais, jurídicos, religiosos, econômicos, mitológicos, estéticos. Podendo informar sobre os mais variados retrospectos de uma sociedade. Ela testemunha determinadas relações culturais importantes para o historiador. Mas também não podemos esquecer que a moeda como documento não é reflexo de um simples aquecimento econômico, e sim trata-se de outro acontecimento paralelo. Uma materialidade constituída por camadas sedimentares de interpretações: "o documento, é assim, pensado arqueologicamente como monumento (Jenkins: 2001, 11).

Donis Dondis afirma que, para os analfabetos, a linguagem falada, a imagem e o símbolo continuam sendo os principais meios de comunicação. E dentre eles apenas o visual pode ser mantido em qualquer circunstância prática. 
(...) isso é tão verdadeiro como tem sido ao longo da história. Na Idade Média

$e$ no Renascimento, o artista servia à Igreja como propagandista...O comunicador visual tem servido ao imperador e ao comissário do povo...a comunicação pictórica dirigida aos grupos de baixo índice de alfabetização, se pretende ser eficaz, deve ser simples e realista (...). (Dondis: 1997, 184)

Pascal Arnaud destaca que nas moedas da Antiguidade Clássica, principalmente durante os séculos IV e V, são comuns, no anverso, a cabeça ou busto do imperador virem cingida por um diadema com o aspecto de simples fita de pérolas com duas ou três pontas (Arnaud: s/d, 195). Trata-se de uma mensagem simbólica específica, cujo significado é o de designar a pessoa do governante.

Ao possuidor romano de uma determinada espécie monetária estranha, esta falava-lhe pelo metal, nobre ou não, em que era cunhada, pelo tipo e pela legenda. O primeiro informava-o a riqueza de um reino e os outros dois elementos diziam-lhes algo sobre a arte, ou seja, o maior ou menor aperfeiçoamento técnico usado no fabrico do numerário circulante, sobre o poder do emissor e, sobretudo, sobre a ideologia político-religiosa que lhe dava o corpo. É dentro deste último aspecto que pretendemos explorar a fonte numismática.

\section{Considerações Finais}

O poder não pode ser apreendido pelo estudo do conflito, da luta e da resistência, a não ser em suas manifestações mais restritas. O poder não é característico de uma classe ou de uma elite dominante, nem pode ser atribuído a uma delas. Para Foucault, o poder é uma estratégia atribuída às funções. O poder não se origina nem na política, nem na economia, e não é ali que se encontram suas bases. Ele existe como uma rede infinitamente complexa de micropoderes, de relações de poder que permeiam todos os aspectos sociais. O poder não se reprime, mas também cria. Dentre todos esses aspectos, o mais polêmico de todos é a constatação de que o poder cria a verdade e, portanto, a sua própria legitimação. Cabe aos historiadores identificar essa produção da verdade como uma função do poder (Hunt: 1995, 46).

Cabe ao historiador identificar e definir as suas fontes, pois o documento não é inócuo e, segundo Le Goff, “... uma montagem consciente ou inconsciente da história, da época, das sociedades que o produziram... esforço para as sociedades históricas para impor ao futuro... determinada imagem de si próprias..." (Le Goff: 1984, 103). É necessário haver uma interdisciplinaridade para ser realizada uma desmontagem da ambivalência documento / monumento, através do próprio ambiente que o produziu, auxiliado pela arqueologia, e não baseado em uma única crítica histórica. 
Os símbolos que habitam a numismática estão dotados sempre de uma clara organização hieroglífica, pois procedem do fato de que essas imagens difundidas se articulam sempre com o idioma figurado, no qual o poder se expressa secularmente. Trata-se, segundo de la Flor, do surgimento de representações de águias, leões, como também de torres, cruzes (Flor: 1995, 183), da fênix, de imperadores ou de personagens pertencentes a uma elite político-econômica, que representam a órbita de ação do poder, chegando ao ponto em que a numismática pode ser definida "como um monumento oficial a serviço do Estado." 5 Lembramos ainda que, como afirma Cassirer, “...em lugar de definir o homem como um animal rationale, deveríamos defini-lo como um animal symbolicum." (Cassirer: 1977, 70). Desse modo, a iconografia, e toda a sua simbologia, aparece de fato como testemunho mais evidente do imaginário das sociedades passadas.

Esses signos mantêm com seu objeto uma relação causal de contiguidade física natural. Como exemplo, podemos citar as letras ou símbolos gregos localizados no campo das moedas. Eles indicam que as amoedações foram realizadas por casas monetárias de origem ou influência cultural grega. Realizando uma comparação com o exergo, comprovamos esta relação. Greenwell, no século XIX, já defendia a posição importante das cidades gregas, principalmente de Cyzicus, como centro de cunhagem (Greenwell: $1887,9)$.

Chartier destaca a importância da interpretação dessa simbologia, chamada por ele de "signos do poder".

"Daí a necessidade de constituir séries homogêneas desses signos do poder: sejam as insignias que distinguem o soberano dos outros homens (coroas, ceptros, vestes, selos, etc.), os monumentos que, ao identificarem o rei, identificam também o Estado, até mesmo a nação (as moedas, as armas, as cores), ou os programas que têm por objetivo representar simbolicamente o poder do Estado, como os emblemas, as medalhas, os programas arquitetônicos, os grandes ciclos de pintura..."(Chartier: 1990, 220). 


\section{Fontes}

\section{Numismática}

Moedas de Diocleciano, Constantino I, o Grande e Constâncio II. Rio de Janeiro: acervo do Museu Histórico Nacional, Medalheiro de Número 3; Lote Número: 11, Lâminas de Números: 2 e lote 16 número 5;

\section{Impressas}

AMIANO MARCELINO. Historia (Rerum Gestarum Libri). Edición de Maria Luisa Harto Trujillo. Madrid: Akal, 2002.

CLAVDIVS CLAVDIANUS. Panegyricus de sexto consulatu Honorii Augusti. Edited with introduction, translation, and literary commentary by Michael Dewar. Oxford: Clarendon Press, 1996.

DION CASIO. Historia Romana. Edición de Domingo Plácido Suarez, Jose Maria Candau Moron y Maria Luisa Puertas Castaños. Madrid: Gredos, 2004.

MUSEU HISTÓRICO NACIONAL. Relatórios anuais de 1934, 1960, 1966 e 1967. texto datilografado.

\section{Dicionários / Enciclopédias / Catálogos / Anais}

ANAIS DO MUSEU HISTÓRICO NACIONAL. VOLUMES 1 / 27. Rio de Janeiro, 1940 / 1995.

CHEVALIER, Jean. GHEERBRANT, Alain. Dicionário de Símbolos. 8a. ed. Tradução: Vera Costa e Silva, Raul de Sá Barbosa, Ângela Melim, Lúcia Melim. Rio de Janeiro: Editora José Olympio, 1997.

GREIMAS, Algirdas J. e COURTÉS, Joseph. Dicionário de Semiótica. Tradução de Alceu D. Lima, Diana L. P. de Barros, Eduardo P. Cañizal, Edward Lopes, Ignacio A. Silva, Maria José C. Sembra, Tieko Y. Miyazaki. São Paulo: Editora Cultrix,1979. 
THE ROMAN IMPERIAL COINAGE. Edited by Harold Mattingly, C.H.V. Sutherland, R.A.G. Carson. V. VI, VII, VIII. London : Spink and Sons Ltda, 1983.

\section{Bibliografia}

ARNAUD, Pascal. Le Commentaire de Documents en Histoire Ancienne. Paris: Belin Sup, S/D.

BERELSON, Bernard. Content Analysis in Communication Research. New York: New York University Press, 1952, p. 78.

CARDOSO, Ciro Flamarion S. e PÉREZ BRIGNOLI, Héctor. Os Métodos da História. 2a. ed. Rio de Janeiro: Editora Graal, 1979.

CASSIRER, E. Antropologia Filosófica. Ensaio sobre o Homem. São Paulo: Mestre Jou, 1977.

CARLAN, Cláudio Umpierre. FUNARI, Pedro Paulo Abreu. Moeda: a numismática e o estudo da História. São Paulo: Annablume, 2012.

CHARTIER, Roger. A História Cultural: entre práticas e representações. Rio de Janeiro: Bertrand, 1990.

DONDIS, Donis A. Sintaxe da Linguagem Visual. Tradução Jefferson Luiz Camargo. 2a ed. São Paulo: Martins Fontes, 1997.

DUBY, Georges. Idade Média, Idade dos Homens: do amor e outros ensaios. São Paulo: Companhia das Letras, 1986, p. 190.

ECO, Umberto. Tratado Geral de Semiótica. Tradução Antônio de Pádua Danesi e Gilson César Cardoso de Souza. São Paulo: Perspectiva, 1980.

FLOR, Fernando R. de La. Emblemas Lectures de La Imagem Simbólica. Madrid: Alianza Editorial, 1995.

FLORENZANO, Maria Beatriz B. Numismática e História Antiga. In: Anais do $1^{\circ}$ Simpósio Nacional de História Antiga. João Pessoa: 1984.

GREENWELL, Willian. The Electrum Coinage of Cyzicus. London: Rollin and Feuardent, 1887.

Revista Heródoto. Unifesp. Guarulhos, v. 01, n. 01. Março, 2016. p. 384-399. 
HUNT, Lynn. A Nova História Cultural. Tradução de Jefferson Luís Camargo. São Paulo: Martins Fontes, 1992.

JENKINS, Keith. A História Repensada. Tradução Mário Vilela. Revisão Técnica Margareth Rago. São Paulo: Contexto, 2001.

LASSWELL, Harold D. et alii (org.). Language of Politics. Studies in quantitative semantics. Cambridge (Mass): Massachusetts Institute of Technology Press, 1965, p.95.

LE GOFF, Jacques. História: Novos Objetos. 3a. ed. Rio de Janeiro: Francisco Alves, 1988.

PASTOUREAU, Michel. Coleurs, images, symboles. Études d'Histoire et d'Anthropologie. Paris: Léopard d’Or, 1988.

VIEIRA, Rejane Maria Lobo. Uma grande coleção de moedas no Museu Histórico Nacional? In: Anais do Museu Histórico Nacional, volume 27, Rio de Janeiro: Museu Histórico Nacional, 1995. 